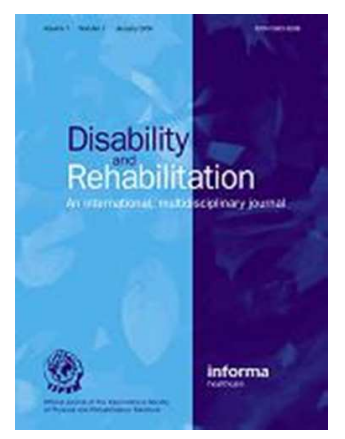

\title{
Personal Experience of Osteoarthritis and Pain Questionnaires: Mapping Items to Themes
}

\begin{tabular}{|r|l|}
\hline Journal: & Disability and Rehabilitation \\
\hline Manuscript ID: & TIDS-10-2012-048.R1 \\
\hline Manuscript Type: & Research Paper \\
\hline Keywords: & Osteoarthritis, Pain, Questionnaires, Experience \\
\hline & \\
\end{tabular}

SCHOLARONE

Manuscripts 


\section{Implications for Rehabilitation}

- Existing questionnaires in pain research may not adequately capture all aspects of the pain experience for osteoarthritis patients

- Patient experience of the healthcare system and their knowledge of the disease appears to be areas particularly neglected in questionnaire-based studies

- latrogenic aspects of the medical system and its impact on pain and mood need to be taken into account more fully when working with patients with osteoarthritis pain

URL: http:/mc.manuscriptcentral.com/dandr Email: davemuller@suffolk.ac.uk 
Abstract

Purpose. The aim of this study was to examine the correspondence between qualitative and quantitative methods of coding experience of pain reported by participants with osteoarthritis (OA) of the knee.

Method. A mapping grid was produced to record the correspondence between subthemes that emerged from thematic analysis of interviews with 24 participants with knee $O A$, and from questionnaire items which were used in a study of 192 knee OA participants. Items were rated according to their degree of correspondence between subthemes and questionnaire items and an overall correspondence score was produced for each subtheme and questionnaire measure.

$\underline{\text { Results. }}$ The subthemes that corresponded well with the questionnaire items were those that related to socio-emotional functioning, the overall experience of pain and the impact of pain on physical functioning. The questionnaire items did not relate to participants' knowledge about their condition and their experience of the medical system.

Conclusions. The study indicated that many aspects of pain experience reported by patients in qualitative interviews are also assessed by commonly used questionnaire outcome measures for people with pain. However, although participants reported that knowledge about their condition and their experience of the medical system were important aspects of the overall pain experience, these are rarely used as outcome measures. Questionnaires that address these additional aspects of the pain experience could be useful to further evaluate the experience of pain and may help to address importance concerns raised by patients with OA of the knee. 
Introduction

Osteoarthritis $(\mathrm{OA})$ is a musculoskeletal disorder characterised by pain, joint damage and inflammation in the surrounding tissue $\left[{ }^{1}\right]$. Millions of people are affected by OA around the world and it is one of the major causes of disability in older adults [ $\left.{ }^{2}\right]$. Pain is the commonest reported problem in people with $\left.\mathrm{OA}^{3}\right]$. This, in turn, can cause psychological distress and impacts many, if not all, areas of social and psychological wellbeing $\left[{ }^{4}\right]$.

Pain researchers interested in exploring the OA experience often employ both qualitative and quantitative approaches. For example, interviews are used to explore the meaning of experiences from the participant's perspective $\left[{ }^{5}\right]$, whilst questionnaire scales are administered to measure levels of state or trait variables $\left[{ }^{6}\right]$. Qualitative research attempts to gain an in-depth understanding of how people make sense of specific phenomena or the world in general $\left[^{7}\right]$. Although a wide range of approaches fall under the qualitative paradigm $\left[{ }^{8}\right]$, some common characteristics exist. These include a focus on the quality of the lived experience and an examination of how people assign meaning to a particular phenomenon $\left[^{7}\right]$. Unlike quantitative approaches, which use statistical methods in order to identify causally meaningful relationships $\left[{ }^{9}\right]$, qualitative research aims to record the totality of the reported experience from the perspective of the participant so that important themes can be ascertained $\left[{ }^{8}\right]$.

Qualitative methods have been widely used in the study of health and illness [see ${ }^{10}$ ], including $\mathrm{OA}\left[\right.$ e.g. $\left.{ }^{11-13}\right]$. In contrast to qualitative research, pain questionnaires attempt to describe and/or quantify the experience of $\mathrm{OA}$ according to statistically refined measurement properties $\left[{ }^{14}\right]$. As the pain experience itself is multidimensional, questionnaires need to incorporate different elements of the experience of pain including pain severity, intensity, duration and quality $\left[{ }^{9}\right]$. Many questionnaires have been developed as outcome measures for studies of the pain experience. Reviews [e.g. ${ }^{15-17}$ ] have identified key psychological domains relevant to pain researchers. These commonly include emotional (e.g. depression, anxiety and distress), cognitive (e.g. self-efficacy, 
helplessness, acceptance and catastrophising) and social context (e.g. pain communication, social support and interaction) variables $\left[{ }^{15}\right]$.

Although mixed-methods research designs are quite common $\left[{ }^{6}\right]$, limited attempts have been made to match the results of quantitative and qualitative approaches within OA pain research. This can be problematic. For example, a large-scale survey conducted with people with chronic pain identified a more extensive range of outcomes (19 in total) that were rated as important compared to those typically used in OA research $\left[{ }^{18}\right]$. Additionally, another study compared outcomes from 60 randomised controlled trials of cognitive and/or behavioural treatment for persistent pain with the 19 domains rated as most important in the Turk et al (2008) study. Only 2 outcomes, physical activities and emotional well-being, were assigned comparable importance by survey respondents and clinician-researchers. Five of the 19 outcomes important to survey respondents were not measured at all and 8 rarely measured $\left[{ }^{19}\right]$. Taken together, these results indicate that in pain research there can often be a significant disjuncture between the priorities of patients compared to clinician/researchers $\left[{ }^{20}\right]$.

One way to prevent this discrepancy from happening is to compare the themes generated from qualitative research with standardised, quantitative outcome measures. As qualitative research is grounded in the experience of participants themselves, it arguably provides a basis by which quantitative questionnaire measures can be compared against actual patient experiences $\left[^{6}\right]$. Furthermore, qualitative methods offer more bredth of experiences to be reported than eliciting responses to a structured set of questions, as in a measurement scale. Although there could be advantages to comparing the results from both methods, as far as the authors are aware, this has not been done in OA research. At the Arthritis Research UK Pain Centre, two studies were conducted with OA participants: a large-scale questionnaire study and a qualitative interview study. We wanted to assess how the questionnaires corresponded to patient experience. The aim of this study therefore was to investigate how participants' experience of $\mathrm{OA}$, captured in a series of semi- 
structured (qualitative interviews) $\left[{ }^{21}\right]$, corresponded to a standard questionnaire set for pain. This was to determine the extent to which the items from the questionnaires mapped onto the thematic structure of the qualitative interview data so as to identify important themes or areas of pain experience that emerged from the semi-structured interviews but may not have been fully captured by the standardised measures.

\section{Method}

Researchers at the Arthritis Research UK Pain Centre conducted a cross-sectional study to examine the measurement properties of a set of questionnaires covering different aspects of pain experience $\left(\right.$ see $\left.^{22}\right)$. The measures were selected on the basis that they covered key domains of pain experience previously identified from large-scale reviews and research guidelines based on expert consensus in OA. A total of 474 people were sent an invitation letter to the study. Participants completed a set of questionnaires including measures of pain, anxiety, depression, fatigue, self-efficacy, acceptance, coping, beliefs, helplessness and quality of life (see below). The questionnaires were completed at home and returned by pre-paid envelope. One hundred and ninety two participants at least partially completed and returned their questionnaire set ( $41 \%$ response rate). All had radiographic evidence of $\mathrm{OA}$ of the knee, scored using Kellgren and Lawrence criteria $\left[{ }^{23}\right]$ and reported pain on most days for at least the past month. The set included: McGill Pain Questionnaire (MPQ) $\left[{ }^{24}\right]$, State-Trait Anxiety Inventory (STAI) $\left[{ }^{25}\right]$, Chronic Pain Acceptance Questionnaire (CPAQ) $\left[{ }^{26}\right]$, RAND Short Form 36 (SF-36) $\left[{ }^{27}\right]$, Beck Depression Inventory II (BDI) $\left[{ }^{28}\right]$, the Intermittent and Constant Osteoarthritis Pain (ICOAP) Questionnaire $\left[{ }^{29}\right]$, the Illness Perceptions Questionnaire-Revised (IPQ-R) $\left[{ }^{30}\right]$, Pain SelfEfficacy Questionnaire (PSEQ) $\left[{ }^{31}\right]$, The Leeds Assessment of Neuropathic Symptoms and Signs (SLANSS) $\left[{ }^{32}\right]$, Coping Strategies Questionnaire (CSQ) $\left[{ }^{33}\right]$, Arthritis Helplessness Index (AHI) $\left[{ }^{34}\right]$, Pain DETECT $\left[{ }^{35}\right]$, Fatigue Severity Scale (FSS) $\left[{ }^{36}\right]$ and the Beliefs about Pain Control Questionnaire (BCCQ) $\left[{ }^{37}\right]$. 
In another study at the Arthritis Research UK Pain Centre, Pouli et al. $\left[{ }^{21}\right]$ conducted a qualitative study with 24 people (17 women and 7 men) with physician-diagnosed knee OA (age range $=48-84$, median age $=62$ ). This study used a larger and more diverse sample than previous qualitative studies, combined with a rigorous methodology, whilst also covering a wider age range including those who had experience of different treatment modalities. Semi-structured interviews were conducted with all participants. The interviews lasted from 30 minutes to one hour, were audio-taped and transcribed verbatim. For the interview question schedule please see Appendix 1. The data were analysed using thematic analysis $\left[{ }^{38}\right]$. Six main themes were identified, with 21 subthemes (see Table 1).

Insert Table 1 about here.

The purpose of the mapping exercise was to examine how the questionnaire items corresponded to the experiences of patients from the qualitative interviews. Data were analysed by a member of the research team at ARUK who had not been involved in either the questionnaire or interview studies. A matrix was developed which had the questionnaire items for each questionnaire listed along the $y$ axis and the subthemes themes from the interviews listed along the $x$ axis (see Table 2). Questionnaire items were rated according to whether they corresponded with each subtheme. The scores 0 or 1 were entered into each box of the matrix, with $0=$ no correspondence (e.g., the item "I get in a state of tension or turmoil as I think over my recent concerns and interests" from the STAI was assessed as having no correspondence with the subtheme beliefs about medical control of pain) and 1 = some correspondence (e.g., "fatigue causes frequent problems for me" on the FSS was assessed as have some correspondence with the subtheme negative emotions/future worries, and the item "There are many activities I do when I feel pain" from the CPAQ was assessed 
as having some correspondence with the subtheme pain omniscience). All the mapped items at the bottom of each column were summed to generate total correspondence scores for each subtheme. Additionally, all the mapped items at the end of each row were summed and the median calculated to get an average correspondence score for each questionnaire measure. A greater score along the row and column denoted higher correspondence between the item and subtheme. These results were then verified by another member of the research team.

Insert Table 2 about here

\section{Results}

Total correspondence score (TCS) for each subtheme are summarised in Table 3.

Insert Table 3 about here

The subthemes that demonstrated higher correspondence with the questionnaire items were pain omnipresence (TCS=209) and negative emotions/future worries (TCS=139). These subthemes dealt with the experience of the overriding sense of pain as being core to $O A$, and the negative emotional impact of having $\mathrm{OA}$ alongside anxieties about future levels of pain and disability, respectively. Other subthemes that were found to correspond strongly with the questionnaire items included: factors that affect pain (TCS=135), a subtheme that dealt with a common range of factors that exacerbate OA pain, including exercise, the weather, weight-bearing etc.; fluctuation of emotions (TCS=116), a subtheme that covered the experience of emotions fluctuating according to 'good and bad days', depending on the amount of pain experienced; and 
keep active (TCS=116), a subtheme that dealt with the experience of trying to keep active and continue engaging with pleasurable activities despite the pain and physical limitations set by knee OA.

The subthemes that demonstrated lower correspondence with the questionnaire items were those that covered the participants' experiences of interacting with the medical health system: negative experiences of the medical team $(\mathrm{TCS}=21)$, positive experiences of the medical team (TCS=22) and limited expectations of treatment (TCS=34). Additionally, the subthemes humour/sarcasm (TCS=20), which denotes the participants' attempts to use humour as a pain management strategy, and beliefs about causes (TCS=38), which describes the participants' knowledge concerning the cause and aetiology of $\mathrm{OA}$, were also found to demonstrate lower correspondence than the other subthemes.

The total correspondence scores for each questionnaire are presented in Table 4.

Insert Table 4 about here

As Table 4 demonstrates, there were a total of 14 questionnaires included in the study and the range of median correspondence scores was between 2.0-15.0. Measures that had a higher correspondence score with the subthemes were the Arthritis Helpless Index (Median=15.0), The ICOAP (Median=14.0), Chronic Pain Acceptance Questionnaire (Median=13.0) and the Pain Selfefficacy Questionnaire (Median=10.0). Questionnaire measures from the set that had the lowest correspondence scores included the S-LANSS (Median=2.0), the McGill Pain Questionnaire (Median=2.0) and the State-Trait Anxiety Index (Median=2.0). 


\section{Discussion and Conclusion}

The experience of pain in $\mathrm{OA}$ is complex and researchers have tried to capture its multidimensional nature through both qualitative and quantitative methods. The purpose of this study was to investigate the aspects of the pain experience that are not captured as well by existing pain questionnaire measures. Overall, and as expected, the questionnaire measures included in our set captured most aspects of the participants' experiences that related to pain, physical and socioemotional functioning. However, and less expected, was the finding that the questionnaire set did not capture so adequately experiences concerning the participants' experiences of the healthcare system and, to a lesser extent, patients' knowledge about arthritis. To the authors' knowledge, this is a novel finding.

The questionnaires were selected to address experiences relating to pain. The interview schedule was also designed to address beliefs about pain. Therefore it is not surprising that there was a reasonable degree of correspondence between the interviews and questionnaires. However, the finding that the subthemes which covered patients' experience of the healthcare system did not correspond as well as some of the other subthemes appears to be a novel finding. There was a strong relational component to participants' experience of the healthcare system in the qualitative interviews. For example, participants' positive experiences of the healthcare system included the positive impact of recommendations made by doctors in terms of managing knee $\mathrm{OA}$, as well as the positive impact of 'being listened to' and offered some hope for the future. For some participants, this increased a sense of control over knee OA. Negative experiences of the healthcare system included being provided with limited information by doctors and reporting a sense of not being 'listened to' and given sufficient attention. As Vowles and Thompson $\left[{ }^{39}\right]$ have pointed out, the patient-provider relationship has a small but remarkably consistent impact on therapeutic outcome across a number of domains and population samples. Indeed, this is one of the more robust findings from psychotherapy research $\left[{ }^{40}\right]$. As previous research has demonstrated, patient outcomes do not 
always coincide very well with clinician/researcher priorities $\left[{ }^{18-20}\right]$. Translating the findings of this study into clinically meaningful outcomes for people with OA would be a valuable area for further research.

The relationship between patients' knowledge about their condition and its impact on treatment outcome is sometimes unclear in pain research $\left[{ }^{41}\right]$. It is also unclear whether an inaccurate or incomplete understanding of their condition actually affects patient satisfaction of treatment $\left[{ }^{42}\right]$. This is perhaps surprising, considering the prominent role of psychoeducation in pain management programmes $\left[{ }^{43-45}\right]$. Beliefs about the relationship between pain and injury when they become unhelpful also form an important part of psychological models of behavioural dysfunctional, e.g., fear-avoidance $\left[{ }^{46}\right]$. This provides the treatment rationale for many cognitive-behavioural interventions in chronic pain $\left[\right.$ see ${ }^{17,47,48}$ ]. Thus, there would seem to be a strong rationale for further research looking at the relationship between these factors, especially in terms of how these factors influence treatment outcome.

Another subtheme from the qualitative interviews which did not map very well with the questionnaire scales was 'humour and sarcasm'. This subtheme denotes the participants' use of laughter as a coping strategy with OA pain. The analgesic effects of laughter for pain have been welldocumented $\left[{ }^{49}\right]$. Also, research in arthritis has suggested that a good sense of humour correlates highly with increased well-being and reduced mood disorders $\left[^{50}\right]$. Somewhat surprisingly, the Pain Coping Strategies Questionnaire contains no items relating to the use of humour or laughter as a coping strategy. Future questionnaires on the psychological aspects of coping with pain may want to consider including items relating to this construct.

Some of the questionnaire measures corresponded better with the participant experiences than other measures. For example, the Arthritis Helpless Index, the ICOAP (The Measure of Intermittent and Constant Arthritis Pain), the Chronic Pain Acceptance Questionnaire and the Pain Self-Efficacy Questionnaire had relatively higher correspondence scores (Medians=15.0, 14.0, 13.0 
and 10.0, respectively) compared with the S-LANNS, McGill Pain Questionnaire, and the State-Trait Anxiety Index (all Medians=2.0). This may reflect the original purposes for which these questionnaires were developed; the Chronic Pain Acceptance Questionnaire and Pain Self-Efficacy Questionnaire and were developed with chronic pain populations $\left[^{26,31}\right]$, whilst the Arthritis Helpless Index and The Measure of Intermittent and Constant Arthritis Pain was specifically developed with arthritis patients $\left[{ }^{29,34}\right]$. In contrast, the S-LANNS $\left[{ }^{32}\right]$ deals with a particular, and very focussed, aspect of pain (i.e. neuropathic pain) and the McGill Pain Questionnaire only focusses on the physical, and not emotional or social, aspect of pain $\left[{ }^{24}\right]$. Finally, the State-Trait Anxiety Index was constructed with physically healthy populations to measure anxiety and not pain $\left[{ }^{25}\right]$ so therefore does not correspond as well.

The current study further highlights limitations in the use of questionnaires developed for one purpose, or in one population, when applied to different research questions in other populations. Indeed, assessing how well patients match up to items on a scale (i.e. how well they match) form the rationale for statistical techniques such as Rasch analysis $\left[{ }^{22}\right]$. However, there is more risk of a potential mismatch between item and construct when the construct under investigation is complex and multidimensional. Pain is a particularly complex concept to measure and so future research needs to take steps to ensure that mismatch is minimised. One way to do this is to apply statistical techniques such as Rasch analysis; another is to map items to themes in a way this study has tried to do.

Mood is another area in which mismatch is possible in pain populations. For example, inclusion of somatic items within depression and anxiety questionnaires may limit their validity in people with chronic pain, where pain rather than psychological state may influence responses $\left[{ }^{51}\right]$. Furthermore, questionnaires developed in clinical populations can be mistargeted in chronic pain populations if the characteristic of interest is generally milder or more pronounced than in the original (developmental) population [ $\left.{ }^{9}\right]$. Researchers have attempted to address these issues in a 
number of ways in research with arthritis patients, e.g., using the BDI without somatic items (see $\left.\left[{ }^{51,52}\right]\right)$, the Health Assessment Questionnaire (HAQ) $\left[{ }^{54}\right]$, or the new Pain Detect for OA patients $\left[{ }^{55}\right]$. Whether this achieves the aim of ensuring validity is a question for debate. Indeed, the Depression, Anxiety and Positive Outlook Scale (DAPOS) was a mood measure developed specifically with chronic pain patients $\left[{ }^{56}\right]$ but, as far as the authors are aware, the measure has not been used expansively in pain research, or been subjected to measurement refinement such as Rasch analysis $\left[{ }^{22}\right]$.

Methodological shortcomings of the present study need to be highlighted. The qualitative analysis was based on a semi-structured interview format that included pre-selected questions to satisfy a particular aim (i.e. to explore the experiences of people coping with OA and to identify the main beliefs about their illness). Although this permitted some degree of focus, it also meant the participants' range of responses were more restricted than they would have been in more openended interview schedules. In addition, it is possible that the 24 participants were not representative of the wider population with $\mathrm{OA}$, even though participants were recruited both from community and secondary care sources, according to a range of treatment experiences. Finally, the mapping was conducted by one researcher and then verified by another. The conclusions may have been stronger with an assessment of inter-rater reliability. However, despite these shortcomings, this research identifies several key issues that require further investigation and hopefully provides a platform upon which further research into the experiences of people with OA can be conducted.

\section{Conclusion}

By mapping quantitative and qualitative studies in OA research, the present study has indicated areas which warrant further investigation within $O A$ and pain research. This includes further in-depth examination of the patient experience of the healthcare system, patient accuracy of understanding about their health condition, and how these factors interact with treatment outcome. 
1

2

3

4

5

6

7

8

9

10

11

12

13

14

15

16

17

18

19

20

21

22

23

24

25

26

27

28

29

30

31

32

33

34

35

36

37

38

39

40

41

42

43

44

45

46

47

48

49

50

51

52

53

54

55

56

57

58

59

60
Such research will help us develop responsive and effective interventions and services for people with $O A$ and pain.

URL: http:/mc.manuscriptcentral.com/dandr Email: davemuller@suffolk.ac.uk 


\section{Declaration of Interest}

The authors report no conflicts of interest. The research was supported by funding from Arthritis Research UK. 
Appendix 1:

\section{Schedule for Semi-Structured Interview}

What is your understanding of your arthritis?

What impact has your arthritis on your life?-in what ways? (Socially? Emotionally?)

How much are you bothered by pain?-example...

How does your pain feel?

(Does your pain come suddenly or is it more predictable?)

Flair ups...

Are there any times that you are pain free?

Have you noticed any factors that make your pain feel worse or better?

Do you have any ideas in terms of what is causing you pain?/caused you arthritis?

Does pain affect other aspects of your life?-are there activities that you have given up because of pain?

How do you feel about that?

Can you please, describe how your pain/OA has progressed over time?

What do you think is happening inside your body to cause you the pain?

How do you see yourself in the future in terms of your condition (OA)?

What effect has treatment had on you?

What do your expect from medical care for your pain?

What makes you satisfied with the treatment?

What makes you dissatisfied with treatment? 


\section{References}

1. Ea H-K, Nguyen C, Bazin D, Bianchi A, Guicheux J, Reboul P, Daudon M, Lioté F. Articular cartilage calcification in osteoarthritis: Insights into crystal-induced stress. Arthritis \& Rheumatism. 2011;63(1):10-18.

2. Brooks PM. Impact of osteoarthritis on individuals and society: how much disability? Social consequences and health economic implications. Current Opinion in Rheumatology [Internet]. 2002;14(5). Available from: http://journals.Iww.com/corheumatology/Fulltext/2002/09000/Impact_of_osteoarthritis_on_individuals_and.17.aspx

3. Dieppe PA, Lohmander LS. Pathogenesis and management of pain in osteoarthritis. The Lancet. 12;365(9463):965-973.

4. Lane NE, Brandt K, Hawker G, Peeva E, Schreyer E, Tsuji W, Hochberg MC. OARSI-FDA initiative: defining the disease state of osteoarthritis. Osteoarthritis and Cartilage. 2011 May;19(5):478-482.

5. Yardley, L. Bishop, F. Delay in seeking help. In: S. Ayers AB, C. McManus SN, K. Wallston JW, R. West, editors. Cambridge handbook of Psychology, Health and Medicine (2nd Edition). Cambridge: Cambridge University Press.

6. Johnson RB, Onwuegbuzie AJ. Mixed Methods Research: A Research Paradigm Whose Time Has Come. Educational Researcher. 2004 October 1 [cited 2012 August 17];33(7):14-26.

7. Elliott R, Fischer CT, Rennie DL. Evolving guidelines for publication of qualitative research studies in psychology and related fields. British Journal of Clinical Psychology. 1999 [cited 2012 August 17];38(3):215-229.

8. Willig C. Introducing qualitative research in psychology adventures in theory and method. 2008. Available from: http://public.eblib.com/EBLPublic/PublicView.do?ptilD=361585

9. Moreton BJ, Wheeler M, Walsh DA, Lincoln NB. Rasch analysis of the intermittent and constant osteoarthritis pain (ICOAP) scale. Osteoarthritis and Cartilage [Internet]. (0). Available from: http://www.sciencedirect.com/science/article/pii/S1063458412008667

10. Baum A, Newman S, Weinman J, West R, McManus C. Cambridge Handbook of Psychology, Health and Medicine. Cambridge University Press; 1997.

11. Kee CC. Living with osteoarthritis: insiders' views. Applied nursing research: ANR. 1998 February [cited 2012 August 17];11(1):19-26.

12. Keysor JJ, Sparling JW, Riegger-Krugh C. The experience of knee arthritis in athletic young and middle-aged adults: an heuristic study. Arthritis care and research: the official journal of the Arthritis Health Professions Association. 1998 August [cited 2012 August 17];11(4):261-270.

13. Sanders C, Donovan J, Dieppe P. The significance and consequences of having painful and disabled joints in older age: co-existing accounts of normal and disrupted biographies. Sociology of Health \& Illness. 2002 [cited 2012 August 17];24(2):227-253.

14. Tennant A, Conaghan PG. The Rasch measurement model in rheumatology: what is it and why use it? When should it be applied, and what should one look for in a Rasch paper? Arthritis and rheumatism. 2007 December 15 [cited 2012 August 24];57(8):1358-1362. 
15. Keefe FJ, Somers TJ. Psychological approaches to understanding and treating arthritis pain. Nature Reviews Rheumatology. 2010 April 1 [cited 2012 August 24];6(4):210-216.

16. Linton SJ, Shaw WS. Impact of psychological factors in the experience of pain. Physical therapy. 2011 May [cited 2012 August 24];91(5):700-711.

17. Gatchel RJ, Peng YB, Peters ML, Fuchs PN, Turk DC. The biopsychosocial approach to chronic pain: scientific advances and future directions. Psychological bulletin. 2007 July [cited 2012 August 24];133(4):581-624.

18. Turk DC, Dworkin RH, Revicki D, Harding G, Burke LB, Cella D, Cleeland CS, Cowan P, Farrar JT, Hertz $S$, et al. Identifying important outcome domains for chronic pain clinical trials: an IMMPACT survey of people with pain. Pain. 2008 July 15;137(2):276-285.

19. Beale M, Cella M, Williams AC de C. Comparing patients' and clinician-researchers' outcome choice for psychological treatment of chronic pain. Pain. 2011 October;152(10):2283-2286.

20. Vlaeyen JWS, Morley S. Cognitive-behavioral treatments for chronic pain: what works for whom? The Clinical journal of pain. 2005 February;21(1):1-8.

21. Pouli, N., Das Nair, R., Lincoln, N.B. The experience of living with knee osteoarthritis: Exploring Illness and treatment beliefs through thematic analysis. Disability and Rehabilitation. Submitted.

22. Moreton BJ, Wheeler M, Walsh DA, Lincoln NB. Rasch analysis of the intermittent and constant osteoarthritis pain (ICOAP) scale. Osteoarthritis and cartilage / OARS, Osteoarthritis Research Society. 2012 October [cited 2012 August 30];20(10):1109-1115.

23. Kellgren JH, Lawrence JS. Radiological Assessment of Osteo-Arthrosis. Annals of the Rheumatic Diseases. 1957 December 1 [cited 2012 August 24];16(4):494-502.

24. Melzack R. The McGill Pain Questionnaire: major properties and scoring methods. Pain. 1975 September;1(3):277-299.

25. Spielberger CD, Gorsuch RL, Lushene RE, Press CP. State-trait anxiety inventory (self-evaluation questionnaire). Consulting Psychololgists Press; 1970.

26. McCracken LM, Vowles KE, Eccleston C. Acceptance of chronic pain: component analysis and a revised assessment method. Pain. 2004 January [cited 2012 August 24];107(1-2):159-166.

27. Hays RD, Sherbourne CD, Mazel RM. The RAND 36-Item Health Survey 1.0. Health economics. 1993 October [cited 2012 August 24];2(3):217-227.

28. Beck AT, Steer RA, Ball R, Ranieri W. Comparison of Beck Depression Inventories -IA and -II in psychiatric outpatients. Journal of personality assessment. 1996 December [cited 2012 August 24];67(3):588-597.

29. Hawker GA, Davis AM, French MR, Cibere J, Jordan JM, March L, Suarez-Almazor M, Katz JN, Dieppe P. Development and preliminary psychometric testing of a new OA pain measure--an OARSI/OMERACT initiative. Osteoarthritis and cartilage / OARS, Osteoarthritis Research Society. 2008 April [cited 2012 August 24];16(4):409-414.

30. Moss-Morris R, Weinman J, Petrie K, Horne R, Cameron L, Buick D. The Revised Illness Perception Questionnaire (IPQ-R). Psychology \& Health. 2002 January [cited 2012 August 24];17(1):1-16. 
31. Nicholas MK. The pain self-efficacy questionnaire: Taking pain into account. European Journal of Pain. 2007 February [cited 2012 August 24];11(2):153-163.

32. Bennett MI, Smith BH, Torrance N, Potter J. The S-LANSS score for identifying pain of predominantly neuropathic origin: validation for use in clinical and postal research. The journal of pain: official journal of the American Pain Society. 2005 March;6(3):149-158.

33. Rosenstiel AK, Keefe FJ. The use of coping strategies in chronic low back pain patients: relationship to patient characteristics and current adjustment. Pain. 1983 September [cited 2012 August 24];17(1):33-44.

34. Nicassio PM, Wallston KA, Callahan LF, Herbert M, Pincus T. The measurement of helplessness in rheumatoid arthritis. The development of the arthritis helplessness index. The Journal of rheumatology. 1985 June [cited 2012 August 24];12(3):462-467.

35. Freynhagen R, Baron R, Gockel U, Tölle TR. painDETECT: a new screening questionnaire to identify neuropathic components in patients with back pain. Current medical research and opinion. 2006 October [cited 2012 August 24];22(10):1911-1920.

36. Krupp LB, LaRocca NG, Muir-Nash J, Steinberg AD. The fatigue severity scale. Application to patients with multiple sclerosis and systemic lupus erythematosus. Archives of neurology. 1989 October [cited 2012 August 24];46(10):1121-1123.

37. Edwards LC, Pearce SA, Turner-Stokes L, Jones A. The pain beliefs questionnaire: an investigation of beliefs in the causes and consequences of pain. Pain. 1992 December [cited 2012 August 24];51(3):267-272.

38. Braun V, Clarke V. Using thematic analysis in psychology. Qualitative Research in Psychology. 2006 January 1;3(2):77-101.

39. Vowles K, Thompson M. The Patient-Provider Relationship in Chronic Pain. Current Pain and Headache Reports. 2012 [cited 2012 August 24];16(2):133-138.

40. Roth A, Fonagy P. What Works for Whom?, Second Edition: A Critical Review of Psychotherapy Research. Guilford Press; 2005.

41. Dworkin RH, Turk DC, Wyrwich KW, Beaton D, Cleeland CS, Farrar JT, Haythornthwaite JA, Jensen MP, Kerns RD, Ader DN, et al. Interpreting the Clinical Importance of Treatment Outcomes in Chronic Pain Clinical Trials: IMMPACT Recommendations. The Journal of Pain. 2008 February [cited 2012 August 24];9(2):105-121.

42. Sitzia J, Wood N. Patient satisfaction: A review of issues and concepts. Social Science \& Medicine. 1997 December [cited 2012 August 24];45(12):1829-1843.

43. Hobson J. Self-Management of Long-Term Health Conditions, A Handbook for People with Chronic Diseases: NHS Expert Patients Programme. Occupational Medicine. 2007 January 1 [cited 2012 August 24];57(1):76-77.

44. Savigny P, Watson P, Underwood M, on behalf of the Guideline Development Group. Early management of persistent non-specific low back pain: summary of NICE guidance. BMJ. 2009 June 4 [cited 2012 August 24];338(jun04 3):b1805-b1805. 
45. van Tulder M, Becker A, Bekkering T, Breen A, Gil del Real M, Hutchinson A, Koes B, Laerum E, Malmivaara A. Chapter 3 European guidelines for the management of acute nonspecific low back pain in primary care. European Spine Journal. 2006 [cited 2012 August 24];15(0):s169-s191.

46. Vlaeyen JW, Linton SJ. Fear-avoidance and its consequences in chronic musculoskeletal pain: a state of the art. Pain. 2000 April [cited 2012 August 24];85(3):317-332.

47. Eccleston C. Role of psychology in pain management. British Journal of Anaesthesia. 2001 July 1 [cited 2012 August 24];87(1):144-152.

48. Turk DC, Gatchel RJ. Psychological Approaches to Pain Management, Second Edition: A Practitioner's Handbook. Guilford Press; 2002.

49. Martin RA. Humor, laughter, and physical health: methodological issues and research findings. Psychological bulletin. 2001 July;127(4):504-519.

50. Skevington SM, White A. Is laughter the best medicine? Psychology and Health. 1998;13(1):157169.

51. Gillespie N, Kirk KM, Heath AC, Martin NG, Hickie I. Somatic distress as a distinct psychological dimension. Social Psychiatry and Psychiatric Epidemiology. 1999 [cited 2012 August 24];34(9):451458.

52. Williams AC, Richardson PH. What does the BDI measure in chronic pain? Pain. 1993 November [cited 2012 August 24];55(2):259-266.

53. Poole H, Bramwell R, Murphy P. Factor Structure of the Beck Depression Inventory-II in patients With chronic pain. The Clinical journal of pain. 2006 December [cited 2012 August 24];22(9):790798.

54. Bruce B, Fries JF. The Health Assessment Questionnaire (HAQ). Clinical and experimental rheumatology. 2005 October;23(5 Suppl 39):S14-18.

55. Hochman JR, Gagliese L, Davis AM, Hawker GA. Neuropathic pain symptoms in a community knee OA cohort. Osteoarthritis and Cartilage. 2011 June;19(6):647-654.

56. Pincus $T$, Williams $A C$ de $C$, Vogel $S$, Field $A$. The development and testing of the depression, anxiety, and positive outlook scale (DAPOS). Pain. 2004 May;109(1-2):181-188. 
Table 1. Summary of themes and subthemes from Pouli et al.

\begin{tabular}{|c|c|c|}
\hline Themes & Subthemes & Brief Description of Subtheme \\
\hline \multirow{5}{*}{ Illness representation } & Pain omnipresence & $\begin{array}{l}\text { The overriding sensation of pain being at the core of people's experience of } \\
\text { living with knee OA }\end{array}$ \\
\hline & Mechanical understanding & $\begin{array}{l}\text { Understanding of OA derived from a medical perspective (e.g. loss of } \\
\text { cartilage, bones that grow abnormally) }\end{array}$ \\
\hline & Factors that affect pain & $\begin{array}{l}\text { A common range of factors that exacerbate OA pain, including exercise, the } \\
\text { weather, weight-bearing etc. }\end{array}$ \\
\hline & Prognosis/ curability & $\begin{array}{l}\text { How participants perceived their condition to progress and specific } \\
\text { expectations about the course of illness (e.g. progressively deteriorating, } \\
\text { linked to old age etc.) }\end{array}$ \\
\hline & Beliefs about causes & $\begin{array}{l}\text { A wide range of beliefs about the possible causes of knee OA, including both } \\
\text { multidimensional and single factor accounts. }\end{array}$ \\
\hline \multirow{2}{*}{$\begin{array}{l}\text { Change in previous } \\
\text { functioning }\end{array}$} & Physical limitations & $\begin{array}{l}\text { Difficulties with physical activities, such as walking, or walking for long } \\
\text { distances, bending, kneeling, going up and down the stairs, standing up for } \\
\text { too long, performing house chores or having difficulties sleeping }\end{array}$ \\
\hline & Social roles/participation & $\begin{array}{l}\text { Changes in previous functioning, in terms of participating in previous } \\
\text { pleasurable leisure activities, and/or a change in performed social roles }\end{array}$ \\
\hline \multirow{3}{*}{ Emotional impact } & $\begin{array}{l}\text { Negative emotions/future } \\
\text { worries }\end{array}$ & $\begin{array}{l}\text { Negative emotions stemming from changes in previous functioning, physical } \\
\text { restrictions or having to deal with intense and constant pain, and/or serious } \\
\text { concerns and worries about the amount of pain expected in the future }\end{array}$ \\
\hline & Impact on identity & $\begin{array}{l}\text { Changes in how participants perceived themselves and how this has affected } \\
\text { their sense of identity }\end{array}$ \\
\hline & Fluctuation of emotions & $\begin{array}{l}\text { Emotions fluctuating according to 'good and bad days' depending on the } \\
\text { amount of pain experienced }\end{array}$ \\
\hline \multirow{2}{*}{$\begin{array}{l}\text { Beliefs about medical } \\
\text { control of pain }\end{array}$} & Pain relief/ partial pain relief & $\begin{array}{l}\text { Relying on a medical control of pain, using pain killers, patches or receiving } \\
\text { steroid injections etc. }\end{array}$ \\
\hline & $\begin{array}{l}\text { Side effects/ dependency/ } \\
\text { ambivalence }\end{array}$ & $\begin{array}{l}\text { Beliefs about the impact of medication, including side effects and } \\
\text { dependency, and a sense of ambivalence towards relying on medication }\end{array}$ \\
\hline
\end{tabular}

URL: http:/mc.manuscriptcentral.com/dandr Email: davemuller@suffolk.ac.uk 


\begin{tabular}{|c|c|c|}
\hline \multirow{5}{*}{ Managing pain and $O A$} & Keep active & $\begin{array}{l}\text { Trying to keep active and continue engaging with pleasurable activities } \\
\text { despite the pain and physical limitations set by knee } O A\end{array}$ \\
\hline & Adjustments/modifications & $\begin{array}{l}\text { Modify activities or use certain strategies to alleviate pain and manage } \\
\text { everyday routines }\end{array}$ \\
\hline & Social support & $\begin{array}{l}\text { 'Important others' who were offering emotional support, and/or relying heavily } \\
\text { on support from friends and family in order to perform everyday tasks, } \\
\text { particularly when physical limitations were severe }\end{array}$ \\
\hline & Life philosophy & $\begin{array}{l}\text { A general philosophy of life, ranging from an active fighting spirit to a more } \\
\text { passive attitude of 'grin and bear it' }\end{array}$ \\
\hline & Humour/Sarcasm & $\begin{array}{l}\text { Using humour or sarcasm when describing experiences of living with knee } \\
\text { OA }\end{array}$ \\
\hline \multirow{4}{*}{$\begin{array}{l}\text { Interactions with the } \\
\text { medical team }\end{array}$} & Positive experiences & $\begin{array}{l}\text { The positive impact of recommendations made by doctors in terms of } \\
\text { managing knee OA, as well as the positive impact of 'being listened to' and } \\
\text { being offered some hope for the future }\end{array}$ \\
\hline & Negative experiences & $\begin{array}{l}\text { Dissatisfaction stemming from either limited information provided by doctors } \\
\text { in terms of options available to manage the condition, or from a sense of not } \\
\text { being 'listened to' and given sufficient attention }\end{array}$ \\
\hline & Limited expectations & $\begin{array}{l}\text { Low expectations in terms of treatment, which resulted in limited or no } \\
\text { contact with medical professionals }\end{array}$ \\
\hline & Impact of diagnosis & $\begin{array}{l}\text { Diagnosis as a positive step towards a more successful management of the } \\
\text { condition }\end{array}$ \\
\hline
\end{tabular}


Table 2. Cross-section of the mapping matrix, used to rate correspondence between items from the questionnaire study and the subthemes from the interview study.

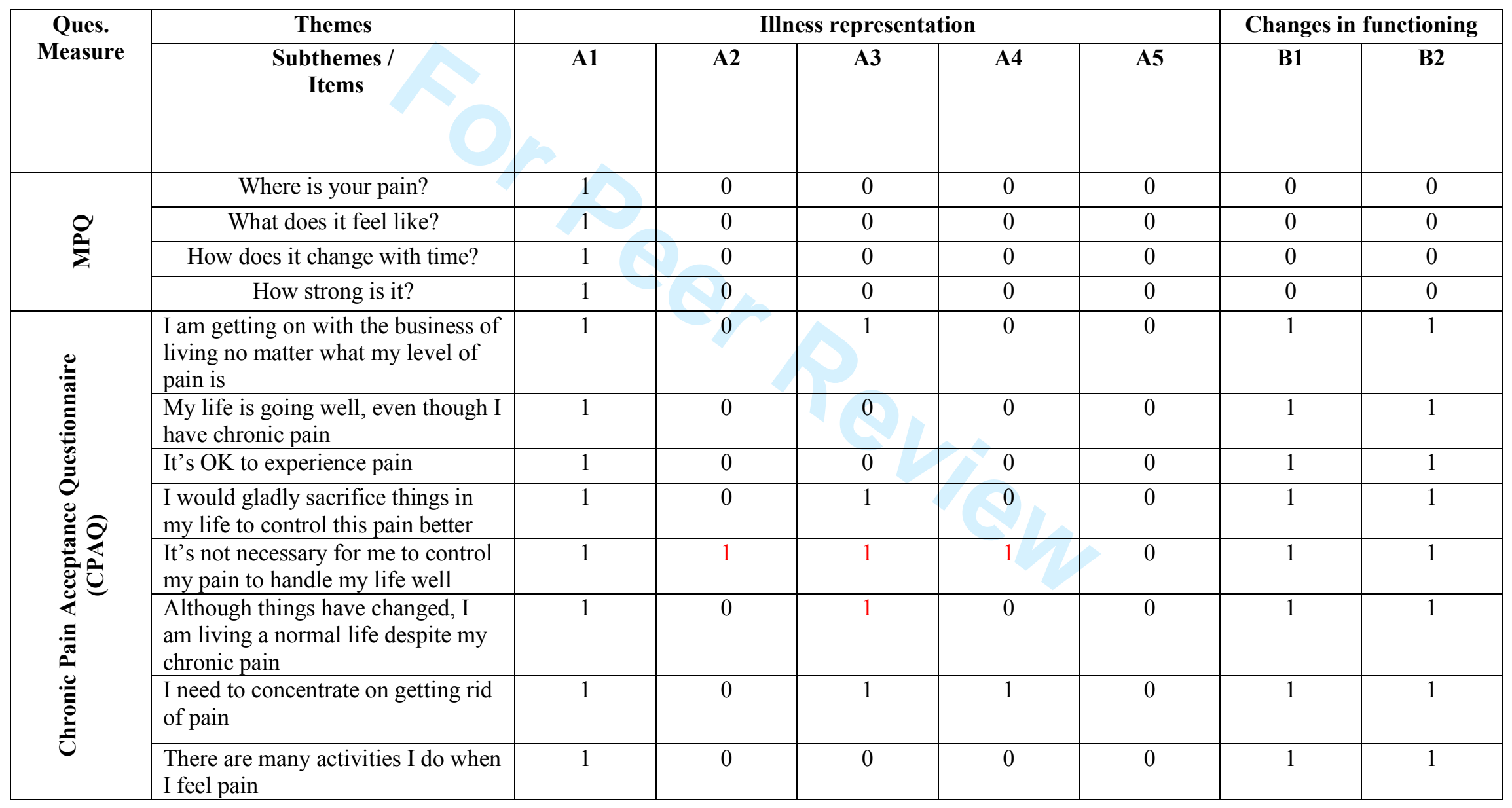




\begin{tabular}{|c|c|c|c|c|c|c|c|}
\hline $\begin{array}{l}\text { I lead a full life even though I have } \\
\text { chronic pain }\end{array}$ & 1 & 0 & 1 & 0 & 0 & 1 & 1 \\
\hline $\begin{array}{l}\text { Controlling pain is less important } \\
\text { than any other goal in my life }\end{array}$ & 1 & 0 & 1 & 0 & 0 & 1 & 1 \\
\hline $\begin{array}{l}\text { My thoughts and feelings about } \\
\text { pain must change before I can take } \\
\text { important steps in my life }\end{array}$ & 1 & 1 & 1 & 1 & 1 & 1 & 1 \\
\hline $\begin{array}{l}\text { Despite the pain, I am now sticking } \\
\text { to a certain course in my life }\end{array}$ & 1 & 0 & 1 & 0 & 0 & 1 & 1 \\
\hline $\begin{array}{l}\text { Keeping my pain under control } \\
\text { takes priority whenever I'm doing } \\
\text { something }\end{array}$ & 1 & 1 & 1 & 0 & 0 & 1 & 1 \\
\hline $\begin{array}{l}\text { Before I can make serious plans, I } \\
\text { have to get some control over my } \\
\text { pain }\end{array}$ & 1 & 1 & 1 & 1 & 1 & 1 & 1 \\
\hline $\begin{array}{l}\text { When my pain increases, I can still } \\
\text { take care of my responsibilities }\end{array}$ & 1 & & 1 & 1 & 0 & 1 & 1 \\
\hline $\begin{array}{l}\text { I will have better control over my } \\
\text { life if I can control my negative } \\
\text { thoughts about pain }\end{array}$ & 1 & 0 & 0 & 1 & 0 & 0 & 0 \\
\hline $\begin{array}{l}\text { I avoid putting myself in situations } \\
\text { where my pain might increase }\end{array}$ & 1 & 1 & 1 & 1 & 1 & 1 & 1 \\
\hline $\begin{array}{l}\text { My worries and fears about what } \\
\text { pain will do to me are true }\end{array}$ & 1 & 1 & 1 & 1 & 1 & 1 & 1 \\
\hline $\begin{array}{l}\text { It's a relief to realise that I don't } \\
\text { have to change my pain to get on } \\
\text { with my life }\end{array}$ & 1 & 1 & 1 & 1 & 0 & 1 & 1 \\
\hline $\begin{array}{l}\text { I have to struggle to do things when } \\
\text { I have pain }\end{array}$ & 1 & 0 & 1 & 0 & 0 & 1 & 1 \\
\hline
\end{tabular}


Table 3. Degree of correspondence between subthemes from Pouli et al (Submitted) and all the items from the questionnaire set. Total score was gained by summing correspondence ratings for each item; higher score indicates greater correspondence.

\begin{tabular}{|c|c|c|}
\hline No. & Subtheme & Total Correspondence Score \\
\hline 1. & Pain Omnipresence & 209 \\
\hline 2. & Negative Emotions / Future Worries & 139 \\
\hline 3. & Factors that Affect Pain & 135 \\
\hline 4. & Fluctuation of Emotions & 116 \\
\hline 5. & Keep Active & 116 \\
\hline 6. & Social Roles / Participation & 112 \\
\hline 7. & Adjustments / Modifications & 109 \\
\hline 8. & Impact on Identity & 105 \\
\hline 9. & Physical Limitations & 101 \\
\hline 10. & Pain Relief / Partial Pain Relief, & 95 \\
\hline 11. & Life Philosophy & 93 \\
\hline 12. & Prognosis / Curability & 80 \\
\hline 13. & Mechanical Understanding & 78 \\
\hline 14. & Impact of Diagnosis & $\left(\mathrm{C}^{2}\right)$ \\
\hline 15. & Social Support & 2 \\
\hline 16. & Side Effects / Dependency / Ambivalence & 57 \\
\hline 17. & Beliefs About Causes & 38 \\
\hline 18. & Limited Expectations & 34 \\
\hline 19. & Positive Experiences of the Medical Team & 22 \\
\hline 20. & Negative Experiences of the Medical Team & 21 \\
\hline 21. & Humour / Sarcasm & 20 \\
\hline
\end{tabular}


Table 4. Medium correspondence score for each questionnaire measure. Higher scores indicate greater correspondence.

\begin{tabular}{|c|c|c|}
\hline No. & Questionnaire Measure & Total Medium Correspondence Score \\
\hline 1. & Arthritis Helpless Index & 15.00 \\
\hline 2. & $\begin{array}{l}\text { The Measure of Intermittent and } \\
\text { Constant Osteoarthritis Pain }\end{array}$ & 14.00 \\
\hline 3. & $\begin{array}{c}\text { Chronic Pain Acceptance } \\
\text { Questionnaire }\end{array}$ & 13.00 \\
\hline 4. & Pain Self-Efficacy Questionnaire & 10.00 \\
\hline 5. & Illness Perception Questionnaire & 08.00 \\
\hline 6. & Fatigue Severity Scale & 07.00 \\
\hline 7. & Pain Questionnaire (BPCQ) & 07.00 \\
\hline 8. & SF-36 & 05.00 \\
\hline 9. & Beck Depression Inventory (II) & 04.00 \\
\hline 10. & Pain Detect & 03.00 \\
\hline 11. & Pain Coping Strategies Questionnaire & 03.00 \\
\hline 12. & State Trait Anxiety Index Form Y-1 & 02.00 \\
\hline 13. & McGill Pain Questionnaire & 02.00 \\
\hline 14. & S-LANSS & 02.00 \\
\hline
\end{tabular}

